\title{
Application of ERIC-PCR for the comparison of isolates of Haemophilus parasuis
}

\author{
M RAFIEE ${ }^{a}, M_{\text {BARA }}^{b}, C^{2}$ STEPHEN $S^{c}$ and PJ BLACKALL ${ }^{a}$
}

\begin{abstract}
Objective To validate a polymerase chain reaction (PCR) based method, Enterobacterial Repetitive Intergenic Consensus-PCR (ERIC-PCR), for the fingerprinting of Haemophilus parasuis strains and to use that method to differentiate isolates from apparently related outbreaks of Glässer's disease on three pig farms.
\end{abstract}

Design ERIC-PCR was evaluated by comparing 15 different strains that represented all 15 recognised serovars in the Kielstein-Rapp-Gabrielson (KRG) scheme for serotyping $H$ parasuis. Next, ERIC-PCR was used to examine 14 Australian field isolates of $H$ parasuis; 12 collected from three farms suffering apparently related outbreaks of Glässer's disease and two from two other farms with no known connection.

Results The 15 serovar reference strains all gave unique, reproducible ERIC-PCR fingerprints. The 12 isolates from the three apparently related outbreaks all gave a single fingerprint, which was distinct from any seen in the 15 serovar reference strains and the two other Australian field isolates in the studied farms. The confirmation that all 12 isolates were the same strain allowed the development of a prevention and control program that has prevented the emergence of any further outbreaks of Glässer's disease on the three farms.

Conclusion ERIC-PCR is a suitable technique for the differentiation of unrelated strains of $H$ parasuis. The finding that the 12 field isolates of $H$ parasuis all shared the same fingerprint is strong evidence that there was a common source of infection on all three farms. This study has shown, for the first time, that ERIC-PCR is a suitable technique for the sub-typing of $H$ parasuis and useful for studying the epidemiology of outbreaks of Glässer's disease.

Aust Vet J 2000;78:846-849

Key words: Pigs, Haemophilus parasuis, genotypic characterisation, molecular epidemiology

lässer's disease, caused by the bacterium $\mathrm{H}$ aemophilus parasuis, is a polyserositis and arthritis of pigs that has a worldwide distribution. ${ }^{1}$ The disease occurs only sporadically in conventionally raised swine, but it has emerged recently as an important cause of morbidity and mortality in SPF pigs ${ }^{1}$ as well as pigs produced by segregated early weaning systems. ${ }^{2}$ The principal lesions associated with the disease are fibrinous or serofibrinous meningitis, serositis, pleuritis, peritonitis and arthritis that can occur in various combination or occasionally singly. ${ }^{1}$

australasian Pig Institute, Queensland Department of Primary Industries, Animal Research Institute, Yeerongpilly, Queensland 4105

bepartment of Farm Animal Medicine and Production, The University of Queensland, Queensland 4072

${ }^{\complement}$ Queensland Department of Primary Industries, Toowoomba Veterianry laboraory, Toowoomba, Queensland 4352
Considerable heterogeneity among $\mathrm{H}$ parasuis isolates has been demonstrated by methods such as serotyping, ${ }^{3}$ colony morphology, ${ }^{4}$ whole cell and outer membrane protein profile ${ }^{5,6}$ and REA of chromosomal D N A. ${ }^{7,8}$ D espite this widespread recognition of intra-species heterogeneity, there have been few studies examining the strains associated with outbreaks of Glässer's disease. Several serotyping studies have reported that different serovars can be present in the one herd at the one time. ${ }^{9,10}$ The REA studies indicated that, in most of the herds examined, isolates with several different REA patterns were present in apparently healthy pigs and that the REA profiles of isolates associated with disease differ from nasal isolates obtained from the same herd. 7,8

PCR-based typing methods are recognised as being far more rapid than either conventional phenotypic typing methods or other DNA typing methods such as REA, ribotyping or PFGE. ${ }^{11}$ Two common variations of PCR fingerprinting are RAPD ${ }^{12}$ and ERIC-PCR. ${ }^{13}$

In this paper we report on our evaluation of the use of ERIC $P C R$ as a method of fingerprinting or discriminating between strains of $\mathrm{H}$ parasuis.

\section{Materials and methods}

Bacteria

Reference strains for $\mathrm{H}$ parasuis serovars 2 to 6 and 8 to 15 were obtained from Dr Vicki Rapp-Gabrielson of Solvay (now Fort D odge, M innesota, USA). Australian field isolates H S145 and HS197, previously shown to be serovars 1 and 7 respectively, ${ }^{10}$ were used as the serovar 1 and 7 reference strains. Twelve Australian field isolates of $\mathrm{H}$ parasuis were also used in this study. These isolates have been previously identified as $\mathrm{H}$ parasuis as previously described. ${ }^{14}$ The isolates had also been shown to be non-typable in the KRG serotyping scheme. ${ }^{15} \mathrm{~A}$ further two Australian field isolates of $\mathrm{H}$ parasuis ( $\mathrm{HSIl}$ and H S72), which had been shown to be $H$ parasuis serovars 5 and 9 respectively ${ }^{9}$ were also included. These latter two isolates were selected as they had no known connection with the other 12 field isolates. Full details of the reference strains and the 14 field isolates used in this study are given in Tables 1 and 2 respectively.

\begin{tabular}{ll} 
ERIC-PCR & $\begin{array}{l}\text { A PCR based on primers that target } \\
\text { Enterobacterial }\end{array}$ \\
& $\begin{array}{l}\text { Repetitive } \text { Intergenic } \\
\text { Polymensus sequences }\end{array}$ \\
PCR & Pulse field gel electrophoresis \\
PFGE & Random Amplification Polymerphic DNA \\
RAPD & Restriction endonuclease analysis \\
REA & Specific pathogen free \\
SPF & \\
\hline
\end{tabular}


Table 1. Serovar reference strains of Haemophilus parasuis used in this study.

\begin{tabular}{cc}
\hline Original Code & KRG Serovar \\
\hline HS145a & 1 \\
SW 140 & 2 \\
SW114 & 3 \\
SW124 & 4 \\
Nagasaki & 5 \\
131 & 6 \\
HS197a & 7 \\
C5 & 8 \\
D74 & 9 \\
H367 & 10 \\
H465 & 11 \\
H425 & 12 \\
IA-84-17975 & 13 \\
IA-84-22113 & 14 \\
SD-84-15995 & 15
\end{tabular}

australian field isolate, previously shown to be the respective serovar. ${ }^{10}$ Used as replacement for the formal reference strains, which were not available.

M edia

The agar medium TM/SN and the broth medium TM B ${ }^{16}$ were used to grow $\mathrm{H}$ parasuisfor preparation of D N A or crude cell lysates.

\section{N A preparation}

Pure DNA preparations were used to establish and validate ERIC-PCR for use with $H$ parasuis. The Puregene DNA I solation K it (G entra systems) was used to extract chromosomal D N A. After initial validation, the ERIC-PCR was then used on crude D N A preparations derived directly from colonies on agar. Briefly, a loopful of overnight bacterial growth on a TM/SN agar plate was harvested into $0.5 \mathrm{~mL}$ of sterile D N A quality water. Tween 20 was added to a final concentration of $0.5 \%$ and three cycles of boiling (for $5 \mathrm{~min}$ ) and cooling on ice (for $2 \mathrm{~min}$ ) were performed. A PCR thermocycler was used for the heating of samples at $98^{\circ} \mathrm{C}$. The samples were centrifuged for $10 \mathrm{~s}$ at $15,000 \mathrm{~g}$ and immediately placed on ice. An aliquot of $4 \mu \mathrm{L}$ of the supernatant was used in the PCR reaction.

\section{ERIC-PCR Typing}

The PCR methods were adapted from a previously published study. ${ }^{11}$ The primers used were ERIC-1R (5'ATGTAAGCTCCTGGGGATTCAC-3') and ERIC-2 (5'AAGTAAGTGACTGGGGTGAGCG-3'). ${ }^{13}$ The GeneAmp PCR Core Reagents K it (Perkin Elmer, USA) was used for the preparation of the reaction mixture. A typical reaction mix contained $5 \mu \mathrm{L}$ of $10 \mathrm{X}$ PCR buffer II (100 mM Tris- $\mathrm{HCl}, \mathrm{pH}$ 8.3; $500 \mathrm{mM} \mathrm{KCl}$ ), $5 \mu \mathrm{L}$ of $25 \mathrm{mM} \mathrm{M} \mathrm{gCl}$, solution, $2 \mu \mathrm{L}$ of each deoxynucleotide triphosphate $(10 \mathrm{mM}), 100 \mathrm{ng}$ of each primer, 1.25 units of Taq DNA polymerase, $4 \mu \mathrm{L}$ of crude D N A template and D N A quality water (sufficient to make final volume up to $50 \mu \mathrm{L}$ ). A Thermal Cycling System (H ybaid, PCR EXPRES, UK ) was used for amplification. The amplification process consisted of an initial denaturation at $95^{\circ} \mathrm{C}$ for 2 min, then 35 cycles consisting of denaturation at $94^{\circ} \mathrm{C}$ for $30 \mathrm{~s}$, annealing at $50^{\circ} \mathrm{C}$ for $30 \mathrm{~s}$ and extension at $72^{\circ} \mathrm{C}$ for $6 \mathrm{~min}$, with a final extension at $72^{\circ} \mathrm{C}$ for $6 \mathrm{~min}$. Amplified
Table 2. Details of the $12 \mathrm{H}$ parasuis field isolates examined in this study.

\begin{tabular}{lccc}
\hline Isolate Code & Farm & ERIC-PCR Type & Serovar $^{\text {b }}$ \\
\hline HS1150 & A & I & NR \\
HS1152 & A & I & NR \\
HS1153 & A & I & NR \\
HS1155 & A & I & NR \\
HS1156 & A & I & NR \\
HS1173 & B & I & NR \\
HS1174 & B & I & NR \\
HS1175 & B & I & NR \\
HS1192 & B & I & NR \\
HS1193 & B & I & NR \\
HS1196 & C & I & NR \\
HS1197 & C & I & NR \\
HS11 & - & II & 5 \\
HS72 & - & III & 9 \\
\hline
\end{tabular}

${ }^{\mathrm{a}} \mathrm{All}$ isolates were shown to be $\mathrm{H}$ parasuis by traditional phenotypic testing. ${ }^{b} \mathrm{NR}=$ no reaction to antisera to serovars 1 to 15 .

products were separated by horizontal electrophoresis through a $1 \%$ agarose gel at $80 \mathrm{~V}$ for $1 \mathrm{~h}$ in Tris-Borate-EDTA buffer ${ }^{17}$ containing ethidium bromide $(0.5 \mu \mathrm{g} / \mathrm{mL})$. A $1 \mathrm{~kb}$ D N A ladder (Gibco-BRL, USA) was used as a marker. Amplified products were visualised and photographed under UV light.

\section{Results}

Field information on outbreak

The outbreak was first observed as sudden death in finisher pigs on Farm A, a 550 sow high health piggery where Glässer's disease had previously been diagnosed. The disease spread within 9 days to the grower pigs. The losses included 35 finisher pigs, 36 grower pigs and 12 weaners. Necropsy findings included pericarditis, peritonitis, pleuritis with interstitial pneumonia, fibrinous meningitis, polyarthritis and occasionally orchitis.

Farm A was providing 200 4-week-old weaner pigs a fortnight to Farm B, a contract grower using Ecoshelters (Clearspan Shelters, Toowoomba). O n Farm B, pigs from Farm A were commingled with pigs of the same age from Farm $D$. Farm $D$ was created by a medicated early weaning program using pigs from Farm $A$. Glässer's disease had never been diagnosed in pigs from Farm $D$.

Two weeks after the G lässer's disease outbreak on Farm A, pigs on Farm $B$ started to die suddenly. M ost of the pigs affected on Farm $B$ were originally sourced from Farm $D$.

The same week, four pigs died on Farm C (another contract pig grower). A further 25 pigs were sick and were treated with injectable penicillin. All pigs were from Farm D. However, previous batches of pigs on Farm C were sourced from Farm A.

Validation of ERIC-PCR typing for $\mathrm{H}$ parasuis

All 15 reference strains of $H$ parasuis gave a unique ERIC$P C R$ finger-print (Figures $1 A$ and $1 B$ ). The fingerprints were reproducible and stable on repeated tests.

Characterisation of the field isolates of $\mathrm{H}$ parasuis

All 12 isolates of $H$ parasuis gave the same ERIC-PCR fingerprint and they were reproducible when they were repeatedly tested. This fingerprint was different from the other 
$1 \mathrm{~A}$

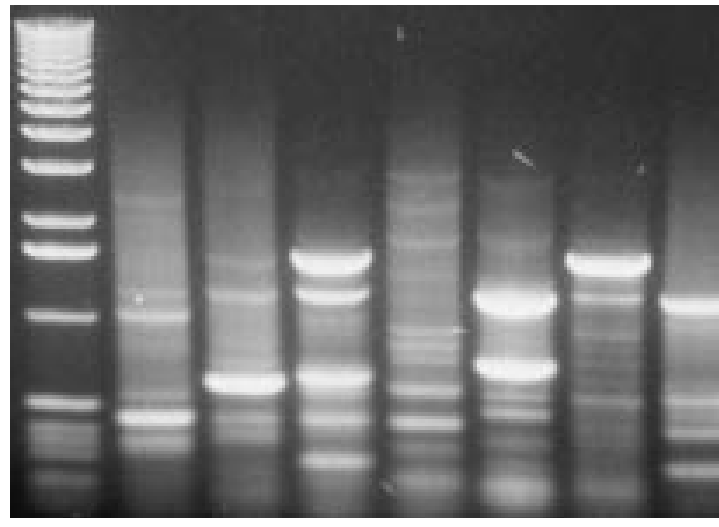

$\begin{array}{lllllllll}\text { A } & \text { B } & \text { C } & \text { D } & \text { E } & \text { F } & \text { G } & \text { H }\end{array}$

$1 \mathrm{~B}$

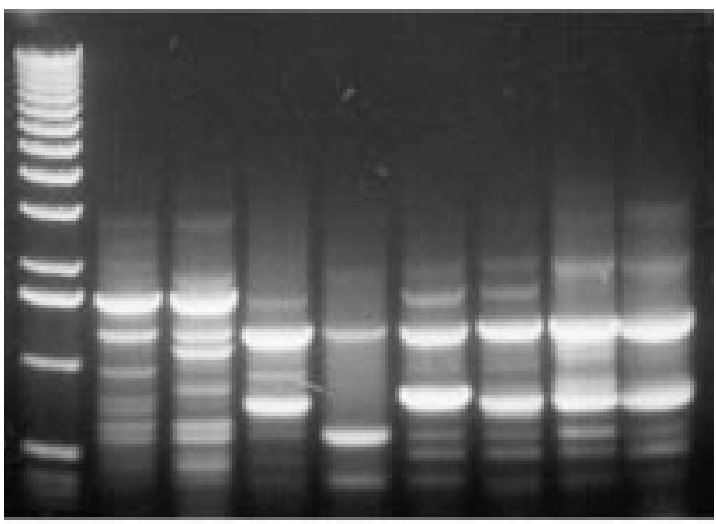

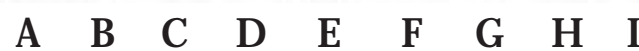

Figure 1. ERIC-PCR fingerprints of the 15 serovar reference strains of $H$ parasuis. 1A. Lane A - Molecular weight marker (1 kb ladder), Lanes B-H - $\mathrm{H}$ parasuis reference strains. Lane B- strain HS145 (serovar 1), lane C - strain SW140 (serovar 2), lane D strain SW114 (serovar 3), lane E - strain SW124 (serovar 4), lane F - strain Nagasaki (serovar 5), lane G - strain 131 (serovar 6), lane H - strain HS1072 (serovar 7). 1B. Lane A - Molecular weight marker (1 kb ladder), Lanes B-I $H$ parasuis reference strains. Lane B strain C5 (serovar 8), lane C - strain D74 (serovar 9), lane D - strain H367 (serovar 10), lane E - strain H465 (serovar 11), lane F - strain H425 (serovar 12), lane G - strain H3IA-84-17975 (serovar 13), lane $H$ - strain IA-84-22113 (serovar 14), lane I strain SD-84-15995 (serovar 15).

two Australian field isolates (H S11 and H S72) and from the 15 serovar reference strains. Figure 2 compares the ERIC-PCR fingerprints of the field isolates.

\section{Discussion}

There have been few epidemiological studies into outbreaks of $\mathrm{G}$ lässer's disease. This is mostly explained by the fact that there have been few methods available to subtype $H$ parasuis. O ne of the most traditional methods for typing bacteria is serotyping. H owever, very few laboratories have the capacity to serotype $\mathrm{H}$ parasuis.

DN A typing methods offer an alternative approach. 0 ur evaluation of ERIC-PCR is only the second method applied for

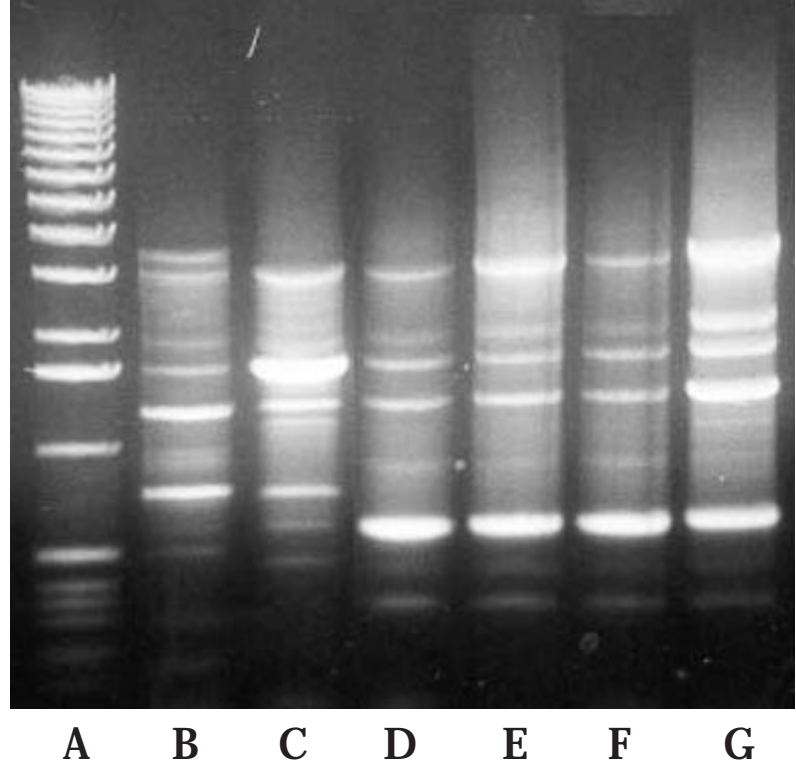

Figure 2. ERIC-PCR fingerprints of the field isolates of $H$ parasuis. Lane A - Molecular weight marker (1 kb ladder), Lanes B-G - H parasuis field isolates. Lane B - isolate HS11 (serovar 5), lane C - isolate HS72 (serovar 9), lane D - isolate HS1150 (nontypable), lane E - isolate HS1152 (nontypable), lane F isolate HS1173 (nontypable), lane G - isolate HS1196

the molecular typing of $\mathrm{H}$ parasuis. The only other method that has been used to date has been REA in two studies in Canada. ${ }^{7,8}$

To validate the use of ERIC-PCR as a typing method for use with $\mathrm{H}$ parasuis, we had to first establish that isolates/strains that are known to be different can be clearly and reproducibly differentiated. As all 15 of the $\mathrm{H}$ parasuis reference strains, which have no known connection and should therefore be quite distinct, gave repeatable unique ERIC-PCR fingerprints, we have shown that ERIC-PCR meets this initial requirement. The previous study of Smart et al ${ }^{7}$ established a similar ability for REA to differentiate serovar reference strains. As the KRG serotyping scheme did not exist at the time, Smart et al ${ }^{7}$ examined the reference strains for the earlier M oruzumi and $\mathrm{N}$ icolet ${ }^{18}$ and the Bakos ${ }^{19}$ serotyping schemes. $\mathrm{M}$ any of the strains of the M oruzumi and N icolet ${ }^{18}$ and the Bakos ${ }^{19}$ schemes are also used in the KRG scheme. ${ }^{3} \mathrm{H}$ ence, both REA and ERIC-PCR appear to show a similar ability to differentiate strains of $\mathrm{H}$ parasuis that are clearly unrelated.

W hen used on the 12 strains associated with the outbreaks on Farms A, B and C, ERIC-PCR showed all 12 isolates to have the same fingerprint. As this fingerprint was markedly different from two other unrelated Australian field isolates as well as the 15 serovar reference strains, this is strong evidence that the 12 isolates from Farms $A, B$ and $C$ are closely related. H ence, ERIC-PCR provided definitive evidence that the Glässer's disease seen on all three farms was due to a single strain that was probably introduced into Farms $B$ and $C$ by the live pigs from Farm A. O ur finding of the spread of $\mathrm{H}$ parasuis by live pigs from farm to farm supports the work of Smart et al ${ }^{7}$ who found that SPF herds with a common source of breeding stock had a much smaller range of different REA patterns in $\mathrm{H}$ parasuis isolates than conventional herds. 
The fact that the 12 isolates of $\mathrm{H}$ parasuis from Farms A, B and $C$ could not be assigned to a recognised $K R G$ serovar illustrates the problem of non-typable strains, which is one of the limitations of serotyping. All three serotyping studies using the KRG serotyping scheme have reported the existence of nontypable strains, varying from 15 to $26 \%, 3,9,10$ This relatively high level of non-typable isolates is accepted as indicating that there are likely to be more serovars than the 15 currently recognised. In contrast, ERIC-PCR will not suffer from the problem of non-typable isolates because all isolates are typable by this method.

A difficulty with serotyping is that finding a collection of isolates as non-typable is not sufficient evidence to conclude that all the isolates are the same. Such a group of non-typable isolates may represent a considerable diversity in which the only common feature is that the isolates fail to react with antisera to the officially recognised serovars. $\mathrm{H}$ ence, the fact that 12 isolates of $\mathrm{H}$ parasuis from Farms $\mathrm{A}, \mathrm{B}$ and $\mathrm{C}$ were all non-typable provided no help in determining whether or not the outbreaks on Farms A, B and C were connected. O nly ERIC-PCR fingerprinting answered the question by providing strong evidence that the three outbreaks were caused by the same strain.

O ur finding of a single, but serologically non-typable, strain in multiple pigs across three farms was a key factor in the management of these outbreaks. Since Farm $D$ had no history of $G$ lässer's disease and pigs from this farm were affected on Farms $B$ and $C$, it was concluded that the pigs from Farm $A$ were spreading $\mathrm{H}$ parasuis to naive pigs sourced from Farm $D$. $\mathrm{H}$ ence, it was recommended that pigs from Farms $A$ and $D$ not be commingled. Further, because it was unknown whether G lasser's disease was present on many of the grower farms, it was recommended that only Farm A pigs be placed with contract growers. This recommendation was based on the concept that naive pigs from Farm $D$ were not suitable for placement on farms with an unknown disease status. It was further recommended that a preventive medication using soluble chlortetracycline be administered in water for five consecutive days following arrival. Since the adoption of these recommendations, only one pig in 600 has developed the clinical signs of meningitis, and this pig quickly recovered following the use of injectable penicillin.

The only other molecular typing studies on G lässer's disease reported to date used the technique of REA.7,8 REA is widely accepted as a very good typing technique but there are considerable practical problems with this technique. The demanding nature of REA is caused by the complexity of the patterns detected, frequently over 100 bands. Comparing isolates by REA requires high quality $D N A$ to ensure complete digestion and excellent electrophoretic technique to resolve the multiplicity of D N A fragments. Possibly due to the difficulty of performing REA, there have been only the two studies of Smart et $\mathrm{al}^{7,8}$ on the use of REA with $\mathrm{H}$ parasuis. In addition, the REA technique used by the $C$ anadian workers involved the use of polyacrylamide gels, a further difficulty when compared with ERIC-PCR which uses simple agarose gels. O verall, while yielding excellent results, REA may only be suitable for use in specialised reference laboratories.

ERIC-PCR can be performed within a shorter time frame than REA because there is no need for pure DN A preparations. There is a need for one specialised piece of equipment, a thermocycler. However, thermocyler technology is now becoming central to many diagnostic assays, and thermocyclers are now commonly available in many diagnostic laboratories. ERIC-PCR fingerprints are considerably easier to examine than the typical REA typing. O verall, ERIC-PCR fingerprinting is a rapid and practical method, which is suited to most modern, well-equipped laboratories. In the current study, we found that ERIC-PCR could be performed using either extensively purified DNA or crude DNA prepared from colonies on agar. Hence, it is possible to complete ERIC-PCR fingerprinting within $24 \mathrm{~h}$ of obtaining a pure culture compared to 3 days for REA typing. O verall, we believe that ERIC-PCR fingerprinting is more suitable for the routine molecular typing of $\mathrm{H}$ parasuis isolates than REA. As shown in the present study, D N A based typing methods can provide very practical information that is of great value in designing and implementing effective prevention and control programs.

\section{Acknowledgments}

The financial support of the Pig Research and D evelopment C orporation is gratefully acknowledged.

\section{References}

1. Nicolet J. Haemophilus parasuis. In: Leman AD, Straw BE, Mengeling WL,

D'Allaire S, Taylor DJ, editors. Diseases of Swine. 6th edn. lowa State University Press, Ames, 1992;526-528.

2. Pijoan C. Pathogenesis of disease in SEW pigs. Pig News Inform 1997; $18: 65 \mathrm{~N}-66 \mathrm{~N}$

3. Kielstein P, Rapp-Gabrielson VJ. Designation of 15 serovars of Haemophilus parasuis on the basis of immunodiffusion using heat-stable antigen extracts. $J$ Clin Microbiol 1992;30:862-865.

4. Morozumi T, Nicolet J. Morphological variations of Haemophilus parasuis strains. J Clin Microbiol 1986;23:138-142.

5. Nicolet J, Krawinkler M. Polyacrylamide gel electrophoresis, a possible taxonomic tool for Haemophilus. In: Kilian M, Frederiksen W, Biberstein EL, editors. Haemophilus, Pasteurella and Actinobacillus. Academic Press, New York, 1981;205-212.

6. Rapp VJ, Ross RF, Nicolet J. Characterization of the outer membrane proteins of Haemophilus parasuis. Proceedings of the Congress of the International Pig Veterinary Society 1986:262.

7. Smart NL, Miniats OP, Mclnnes J. Analysis of Haemophilus parasuis isolates from southern Ontario swine by restriction endonuclease analysis. Can J Vet Res 1988:52:319-324.

8. Smart NL, Hurnik D, Maclnnes JI. An investigation of enzootic Glasser's disease in a specific-pathogen-free grower-finisher facility using restriction endonuclease analysis. Can Vet J 1993;34:487-490.

9. Rapp-Gabrielson VJ, Gabrielson DA. Prevalence of Haemophilus parasuis serovars among isolates from swine. Am J Vet Res 1992;53:659-664.

10. Blackall PJ, Rapp-Gabrielson VJ, Hampson DJ. Serological characterisation of Haemophilus parasuis isolates from Australian pigs. Aust Vet J 1996;73:93-95. 11. Appuhamy S, Parton R, Coote JG, Gibbs HA. Genomic fingerprinting of Haemophilus somnus by a combination of PCR methods. J Clin Microbiol 1997;35:288-291.

12. Chaslus-Dnacla E, Lesage-Descauses MC, Leroy-Sétrin S et al. Validation of random amplified polymorphic DNA assays by ribotyping as tools for epidemiological surveys of Pasteurella from animals. Vet Microbiol 1996;52:91102.

13. Versalovic J, Koeuth T, Lupski JR. Distribution of repetitive DNA sequences in eubacteria and application to fingerprinting of bacterial genomes. Nucleic Acids Res 1991;19:6823-6831.

14. Eaves LE, Blackall PJ, Fegan M. Characterisation and antimicrobial sensitivity of haemophili isolated from pigs. Aust Vet $J$ 1989;66:1-4.

15. Rafiee M, Blackall PJ. Establishment, validation and use of the KielsteinRapp-Gabrielson serotyping scheme for Haemophilus parasuis. Aust Vet $J$ 2000;78:172-174.

16. Reid GG, Blackall PJ. Comparison of adjuvants for an inactivated infectious coryza vaccine. Avian Dis 1987;31:59-63.

17. Sambrook J, Fritsch EF, Maniatis T. Molecular Cloning: A Laboratory Manual. Cold Spring Harbor Laboratory Press, Cold Spring Harbor, 1989.

18. Morozumi T, Nicolet J. Some antigenic properties of Haemophilus parasuis and a proposal for serological classification. J Clin Microbiol 1986;23:10221025.

19. Bakos K. Studien über Haemophilus suis, mit besonderer Berücksichtigung der serologischen. Differenzieriung seiner Stämme [DVM thesis]. University of Stockholm, Stockholm, 1995.

(Accepted for publication 28 July 2000) 